\title{
\%
}

Raquel Martínez Farreres*

Pedro Antonio Merino García**

\section{EL MERCADO DEL GAS NATURAL: VISIÓN GENERAL Y ANÁLISIS DEL MERCADO EUROPEO}

En este artículo se pretende analizar el estado del mercado del gas global, con especial atención al caso del mercado europeo. Se analizará el contexto no solo energético, sino también geopolítico, que han dado como resultado la situación actual: un mercado de gas tensionado y desequilibrado cotizando a precios astronómicos. Finalmente, se incluirá un resumen de las previsiones a corto y largo plazo proporcionadas por la Agencia Internacional de la Energía (AIE) en su último reporte World Energy Outlook (WEO), con el ánimo de esclarecer el papel que se espera que desempeñe el gas natural en el proceso de transición de los modelos energéticos.

Palabras clave: gas natural, precios, demanda, producción, Europa, Rusia, GNL.

Clasificación JEL: Q40, Q43, L95.

\section{El mercado del gas natural}

\subsection{Evolución reciente de los precios}

La continua subida de los precios globales de la energía nos ha llevado a una situación crítica que podría tener importantes repercusiones a corto plazo. Si bien la primera fuente energética que experimentó una fortísima subida fue el gas natural, el contagio a otras fuentes alternativas como el carbón o el petróleo no se ha hecho esperar demasiado, de modo que estos también han experimentado una significativa subida de sus precios. El año está

\footnotetext{
* Analista de Energía/Gas Natural-GNL del Servicio de Estudios de Repsol.

** Director del Servicio de Estudios de Repsol.

Versión de diciembre de 2021.

DOI: https://doi.org/10.32796/bice.2022.3142.7337
}

finalizando con promedios de precios del gas en máximos históricos y con algunas incógnitas aún sin resolver.

¿Por qué han seguido aumentando los precios?

Durante el segundo semestre del año la demanda asiática ha continuado creciendo, en parte debido al aumento de la actividad industrial que incrementó la demanda de gas para generación y en parte debido a otros factores: restricciones a la generación con carbón, una menor entrada de la energía nuclear y la pretensión de rellenar los inventarios de gas de forma anticipada desencadenando, precisamente, lo que se trataba de evitar, un repunte desmesurado de los precios.

Pero este aumento de la demanda de gas no ha sido exclusivo de Asia. En algunos $\square$ 
países de América del Sur, principalmente en Brasil, el estrés hidrológico llevó a una mayor dependencia del gas, es decir, a un mayor consumo del esperado también en esta región.

Adicionalmente y a pesar de las ampliaciones de capacidad productiva en EE. UU., las paradas por mantenimiento, los cortes de suministro y las reducciones temporales de la producción en Argelia, Australia, Nigeria, Noruega, Perú, Trinidad y Tobago y el propio EE. UU. han añadido tensión adicional al mercado, estresando los niveles de inventarios, particularmente los de Europa.

Europa, anteriormente bautizada como el «equilibrador de mercado del gas natural global», capaz de absorber grandes volúmenes de GNL (gas natural licuado) en momentos de sobreproducción, se ha visto en los últimos meses en la situación contraria. Los coletazos del pasado invierno, con el frío prolongándose más de lo habitual, la recuperación económica, una menor entrada de renovables en el mix de generación y una producción doméstica en declive, dejaron los inventarios en mínimos históricos en el tercer trimestre de 2021. Durante el primer semestre del año, la situación se palió con aumentos en el suministro por gasoducto procedente de Argelia, Azerbaiyán y Rusia (estos, en niveles por debajo de los registrados en 2019). Pero durante la segunda mitad del año, las tensiones geopolíticas se acentuaron con Rusia, sin reservar capacidad adicional a través de Ucrania y presionando para lograr la puesta en marcha del Nord Stream 2, al mismo tiempo que se dejó de recibir gas de Argelia a través del Magreb-Europa. Malas noticias para el maltrecho balance del gas.

Así, noviembre finalizó con los precios de los principales indicadores del gas global en máximos históricos, superando ampliamente los niveles vistos en el mes anterior. Los indicadores europeos se mantuvieron en $\triangleright$

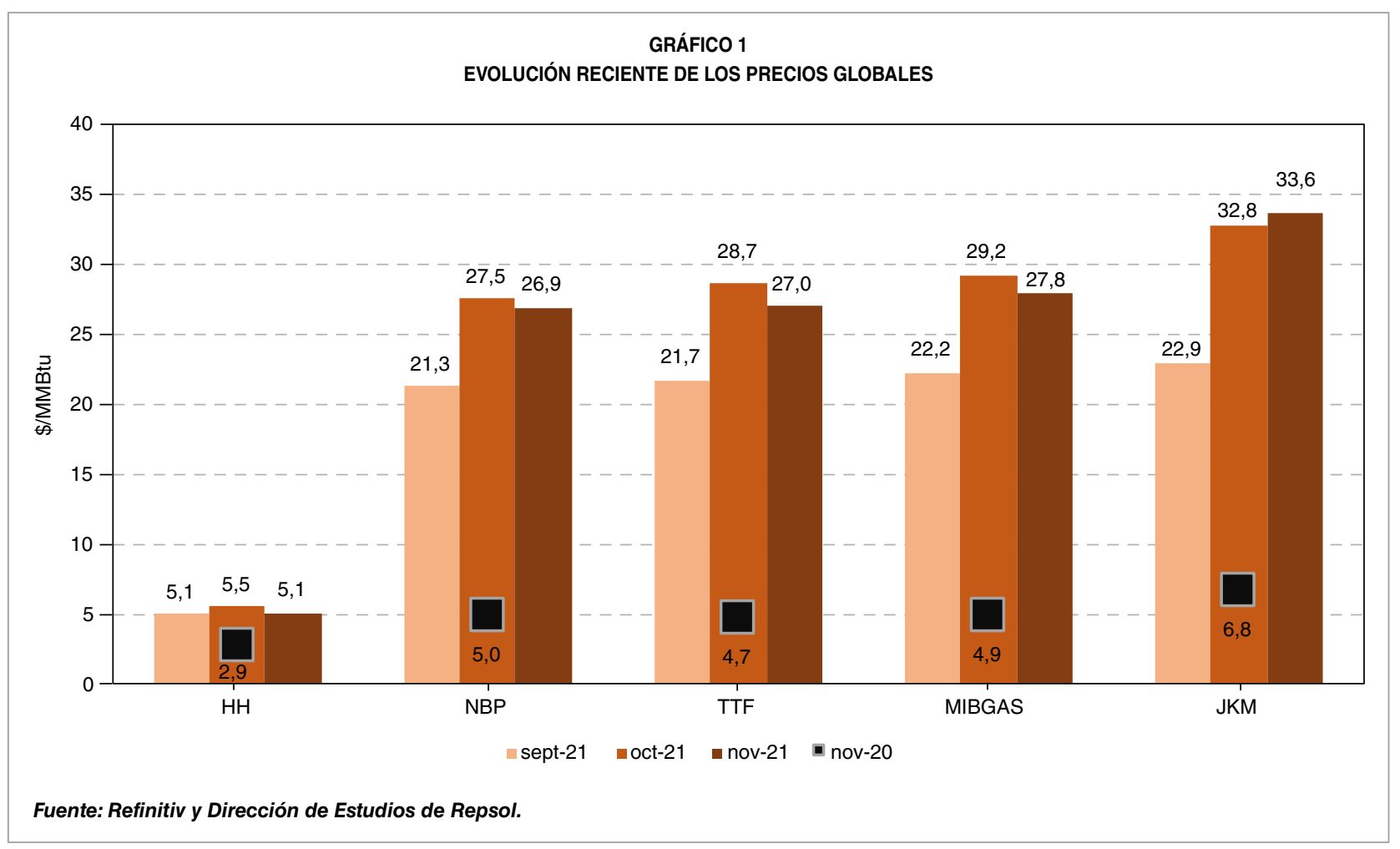




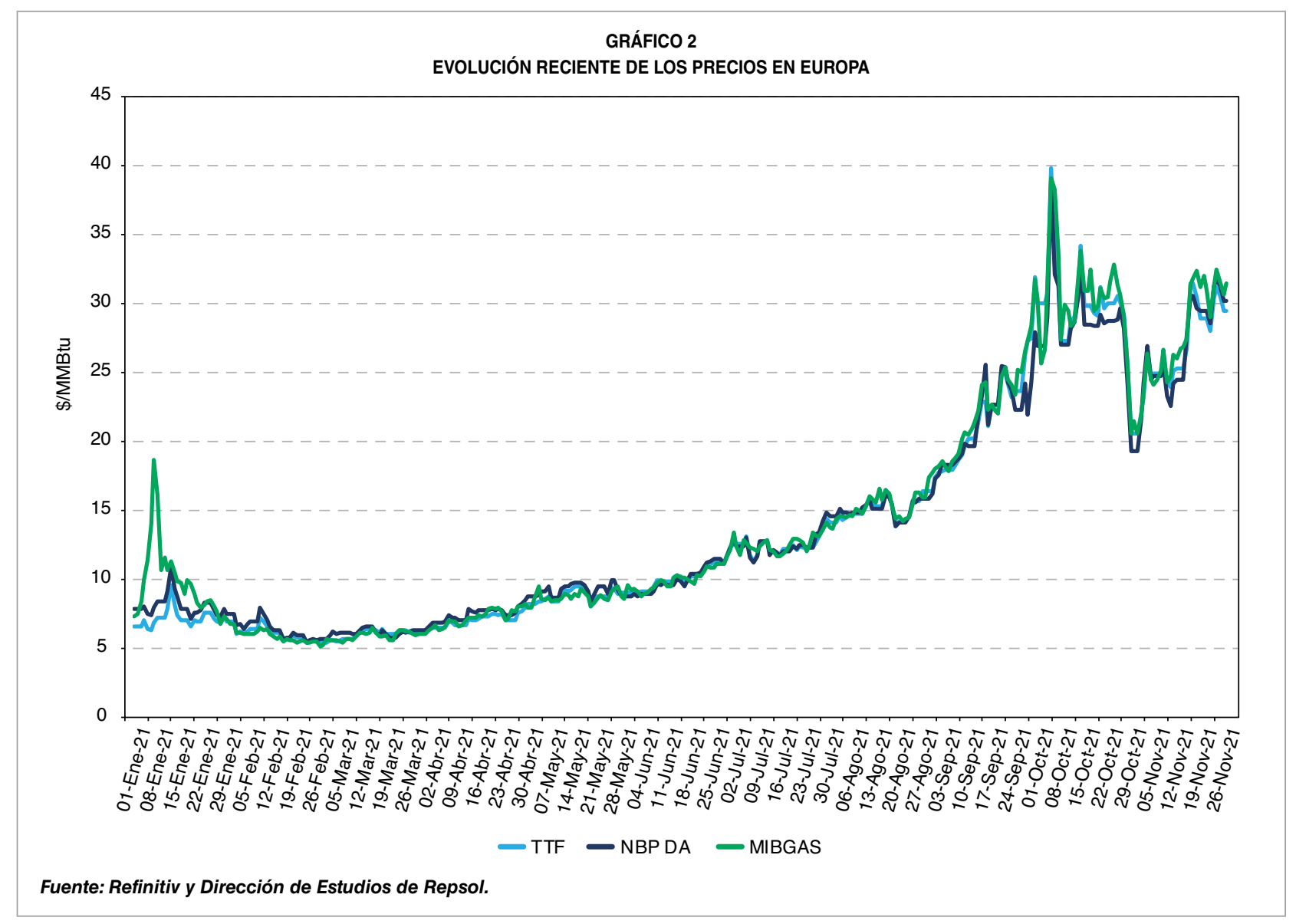

promedio por debajo del JKM (precio JapanKorea-Marker), que vio aumentado su diferencial respecto a Europa entre 4 y 5 dólares. Por su parte el IHH (índice de Herfindahl e Hirschman), se situó en un promedio de 5 \$/MMBtu, si bien rompió puntualmente los $6 \$$ a cierre diario y de forma ocasional.

En Europa, el mes finalizó con todos los indicadores de precios alineados por encima de los 30 \$/MMBtu, y superó una fuerte corrección a finales del mes de octubre. Esta corrección se debió al anuncio de Rusia de comenzar a inyectar gas en Europa, a un aumento de la producción de Noruega y a la previsión de una mayor recepción de cargas de GNL durante el mes de noviembre. EI MIBGAS (Mercado Ibérico del Gas), que estuvo marcando «techo de cotización» por encima del índice holandés TTF durante buena parte del mes, cerró octubre ligeramente por debajo, una vez clarificado cómo se va a recibir el gas procedente de Argelia.

Noviembre fue otro mes de volatilidad intradiaria y diaria, aunque en menor medida que el mes de octubre, cuando se registró una volatilidad sin precedentes que empujó los precios a máximos históricos (5 de octubre). Las preocupaciones acerca del escaso nivel de inventarios de gas, la falta de reserva de capacidad adicional por parte de Rusia y una demanda mayor, resultado de la progresiva caída de las temperaturas típica del invierno, mantuvieron los precios elevados y muy por encima de los promedios históricos.

A corto plazo, se espera que al menos hasta marzo los precios continúen altos en respuesta a la demanda estacional, estrechamente $\square$ 
dependiente de lo frío que sea el invierno, y a que se resuelvan todas las incógnitas acerca del suministro que reciban Europa y Asia.

\subsection{Contexto de mercado del gas natural: especial Europa}

Dado el importante rol que juega Europa en el mercado del gas natural global, a continuación analizaremos con detalle la situación en la que se encuentra (dato cerrado a noviembre de 2021).

\subsubsection{Oferta}

\section{Producción}

La producción de gas natural en Europa habría finalizado en noviembre en niveles en torno a los $5.800 \mathrm{Gwh} / \mathrm{d}$, tras experimentar un incremento del $7 \%$ frente a octubre, pero con un declino entre el 1 y el $13 \%$ frente al mismo mes de 2020 y 2019, respectivamente.

La producción de gas natural en Europa habría aumentado gracias a las contribuciones de Reino Unido, Noruega y Países Bajos. En el caso de Reino Unido, continúa el aumento de la producción iniciado el pasado mes de junio, con unos volúmenes que se habrían más que duplicado. Por su parte, a pesar del aumento registrado en Noruega, este habría sido inferior a lo previamente esperado, debido a diversas interrupciones en el suministro que habrían mantenido la producción de noviembre en niveles aproximados de $3.550 \mathrm{GWh} / \mathrm{d}$, por debajo de los niveles medios para este mes de los últimos tres años, alrededor de $100 \mathrm{GWh} / \mathrm{d}$ más.

A su vez, la producción procedente de Países Bajos habría experimentado un repunte $D$

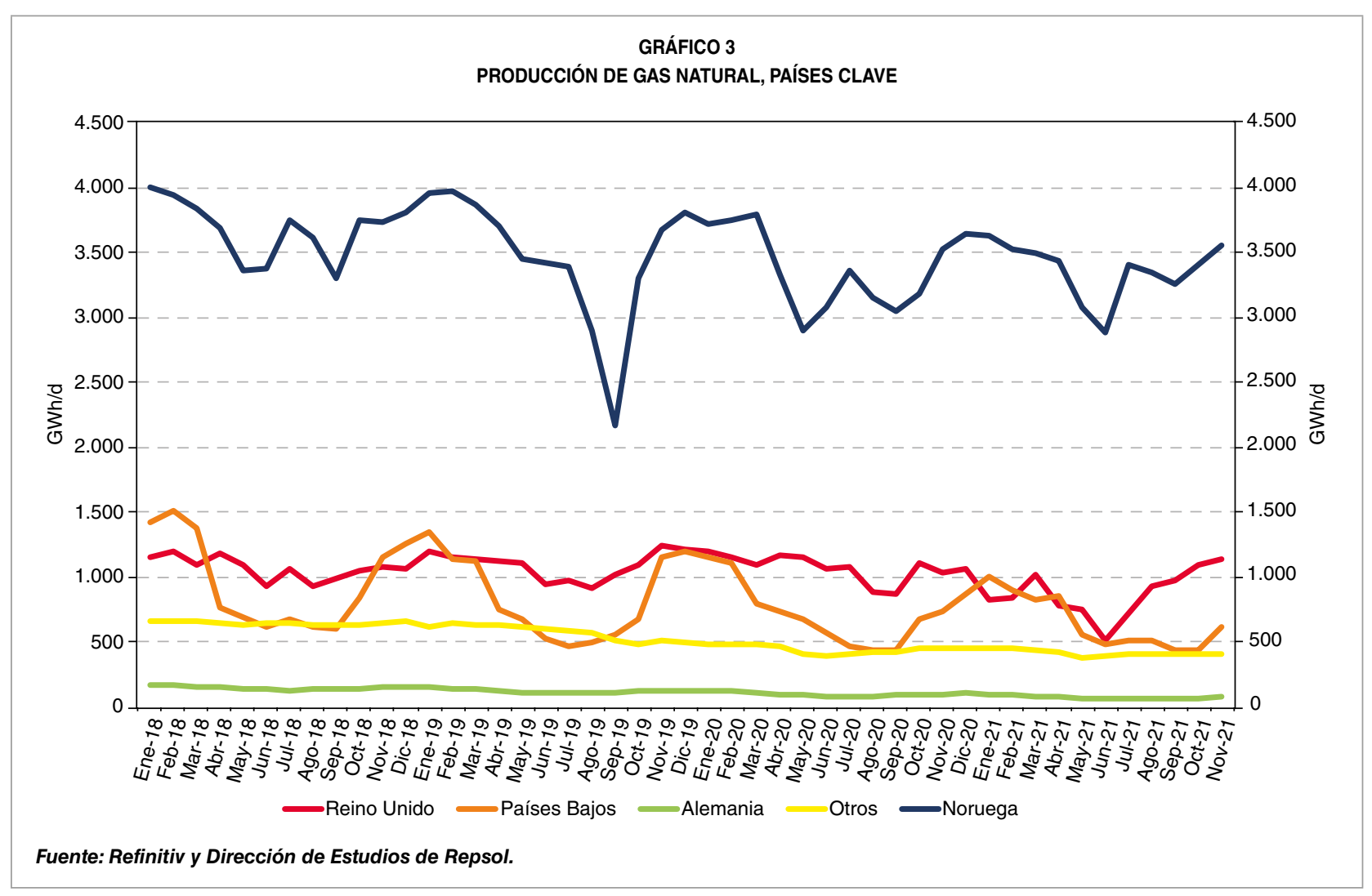


frente a octubre superando los $600 \mathrm{GWh} / \mathrm{d}$, lo que confirmaría la ejecución del aumento temporal y extraordinario de las cuotas para paliar el déficit de gas de cara al invierno.

\section{Importaciones}

Las importaciones de gas se habrían colocado cerca de los $8.900 \mathrm{GWh} / \mathrm{d}$ en noviembre, un $3 \%$ más que las registradas en el mes anterior y un $12 \%$ desde los mínimos anuales, por debajo de los $8.000 \mathrm{GWh} / \mathrm{d}$ de julio. A pesar del aumento, las importaciones continúan un $7 \%$ por debajo de los niveles registrados en 2020.

La tendencia de recepción de gas se mantiene alcista gracias a la mayor entrada de GNL (UK+Continental) durante noviembre. Este aumento habría compensado la falta de gas procedente de Rusia, que, de nuevo, envió volúmenes muy inferiores a los esperados.
La oferta rusa ha sido clave en la fuerte volatilidad observada en los precios durante el mes de noviembre. El suministro a través de las tres rutas principales se mantuvo, en promedio, sin cambios relevantes respecto al mes anterior, aunque se experimentaron cambios importantes en las dinámicas de flujos a través de Mallnow y Velke Kapusany. El suministro físico a través del gasoducto Yamal-Europa cayó a cero en los primeros días de noviembre. Como consecuencia, se activó la retroversión de flujos y Alemania pasó de importar a exportar gas en Mallnow, una situación «extraordinaria».

Sin embargo, desde el 9 de noviembre, los flujos de Velke Kapusany han aumentado hasta niveles de $1.000 \mathrm{GWh} / \mathrm{d}$, en línea con las declaraciones de la empresa gasista rusa y su promesa de comenzar a inyectar gas en los inventarios de Europa tras finalizar el programa de inyección nacional. Los datos de almacenamiento $\triangleright$

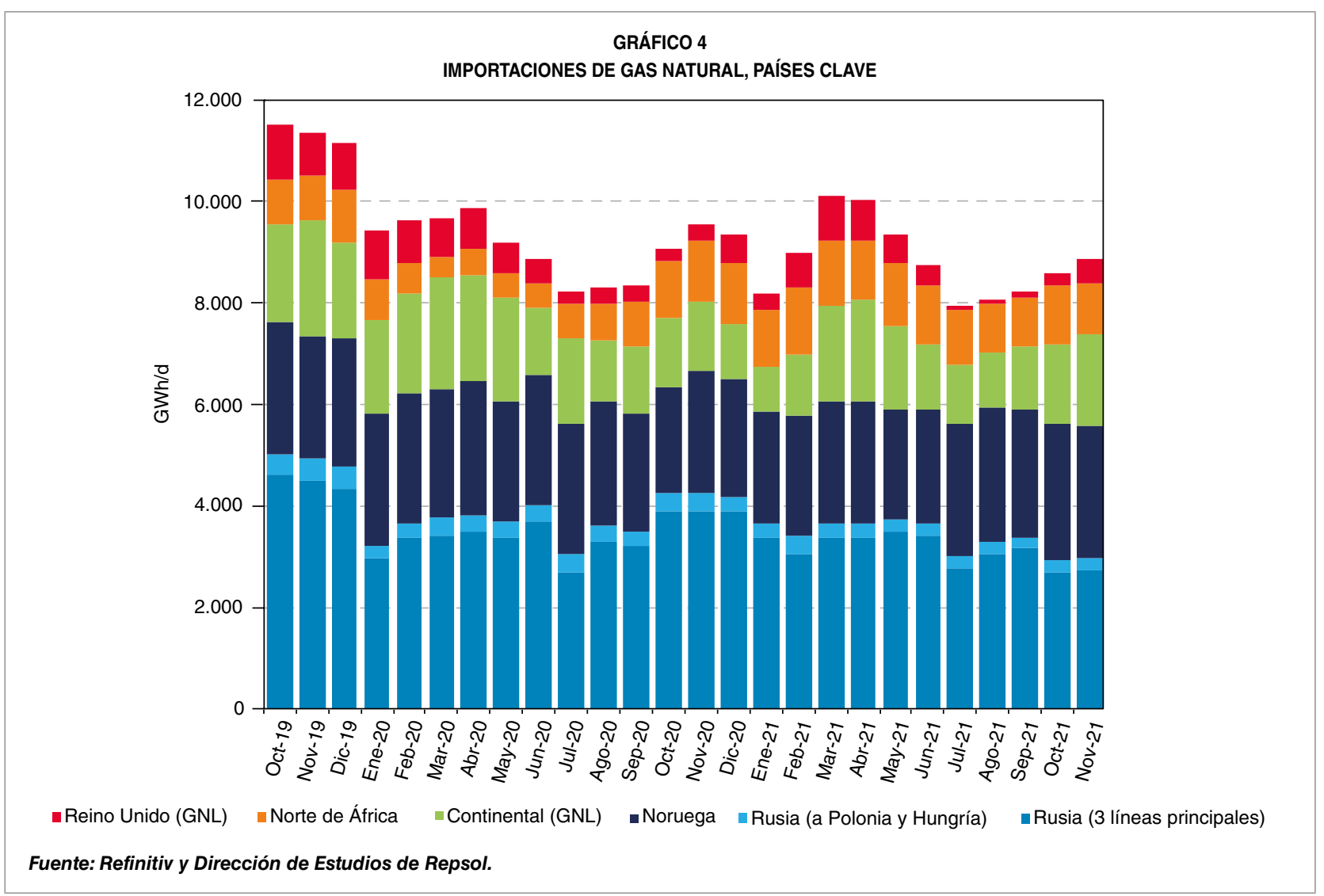


indican que varias instalaciones donde Gazprom tiene capacidad han estado inyectando gas desde el 9 de noviembre, aunque a un ritmo muy lento. Se calcula que entre el 9 y el 16 de noviembre se habrían inyectado alrededor de 700 GWh, pero es una estimación más.

\subsubsection{Demanda}

La demanda de gas en el noroeste de Europa, generalmente utilizada para explicar las tendencias de la demanda del agregado europeo total, ha experimentado cierta recuperación durante el mes de noviembre, aunque continúa por debajo de la registrada en los últimos años, y se situaría en poco más de $6.700 \mathrm{GWh} / \mathrm{d}$, todavía un $2 \%$ por debajo de la vista en 2020 .

La recuperación registrada respecto a octubre se habría producido gracias a un mayor consumo en el sector residencial/comercial, fruto de unas temperaturas más frías y de cierto repunte en el consumo industrial, que habrían compensado las caídas en el consumo para generación, donde se ha mantenido la reversión del switch, pasando de generar con gas a generar con fuel y carbón.

\subsubsection{Inventarios}

Durante el mes de noviembre, se ha consolidado la liberación de inventarios en Europa, a medida que las temperaturas más frías han reactivado la demanda de gas y las importaciones por tubería se han mantenido limitadas. Los inventarios agregados de gas europeos finalizaron el mes de noviembre por debajo del $70 \%$ de su capacidad de llenado, en niveles de $780 \mathrm{Twh}$, frente al $89 \%$ en noviembre de 2020 .

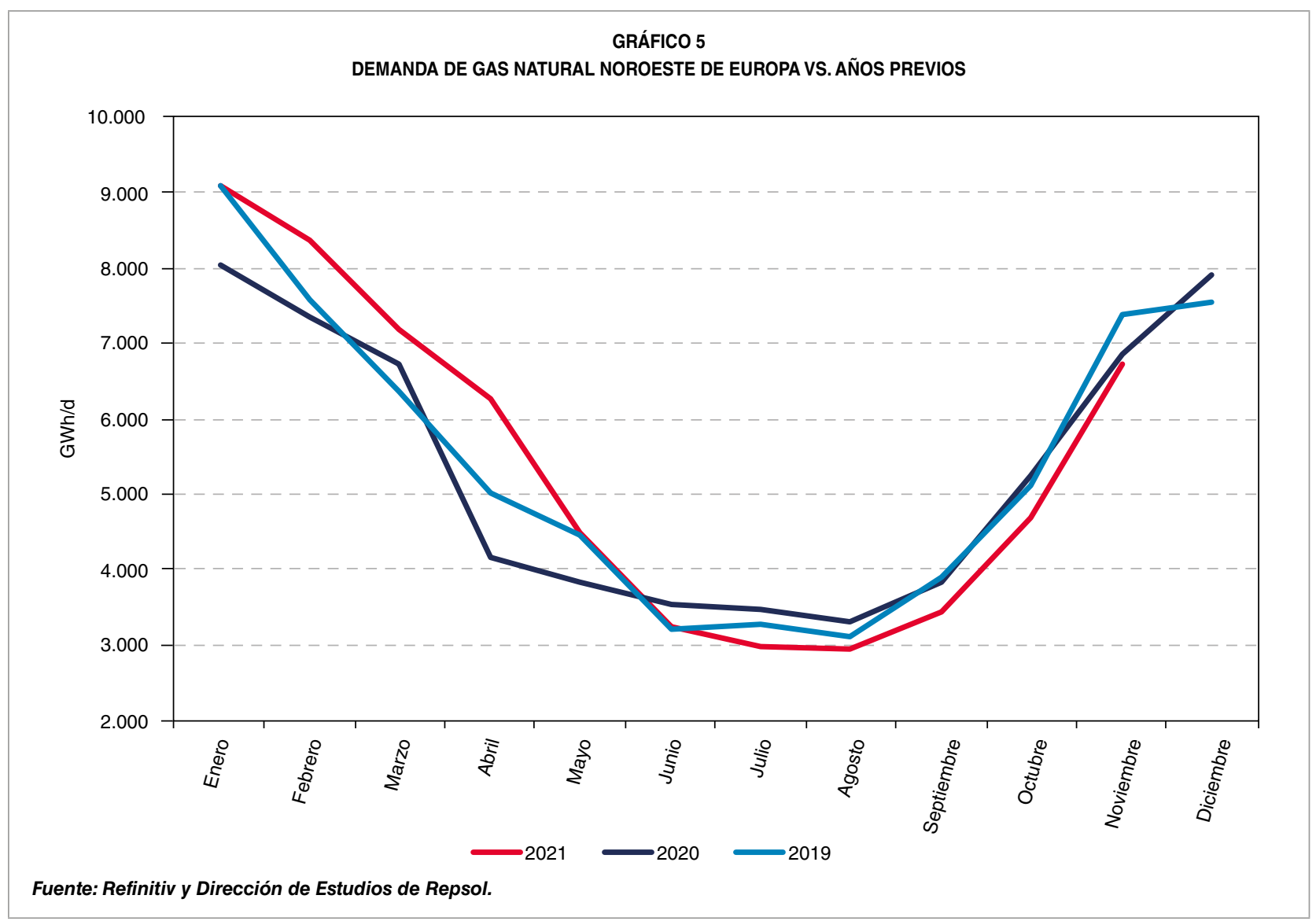




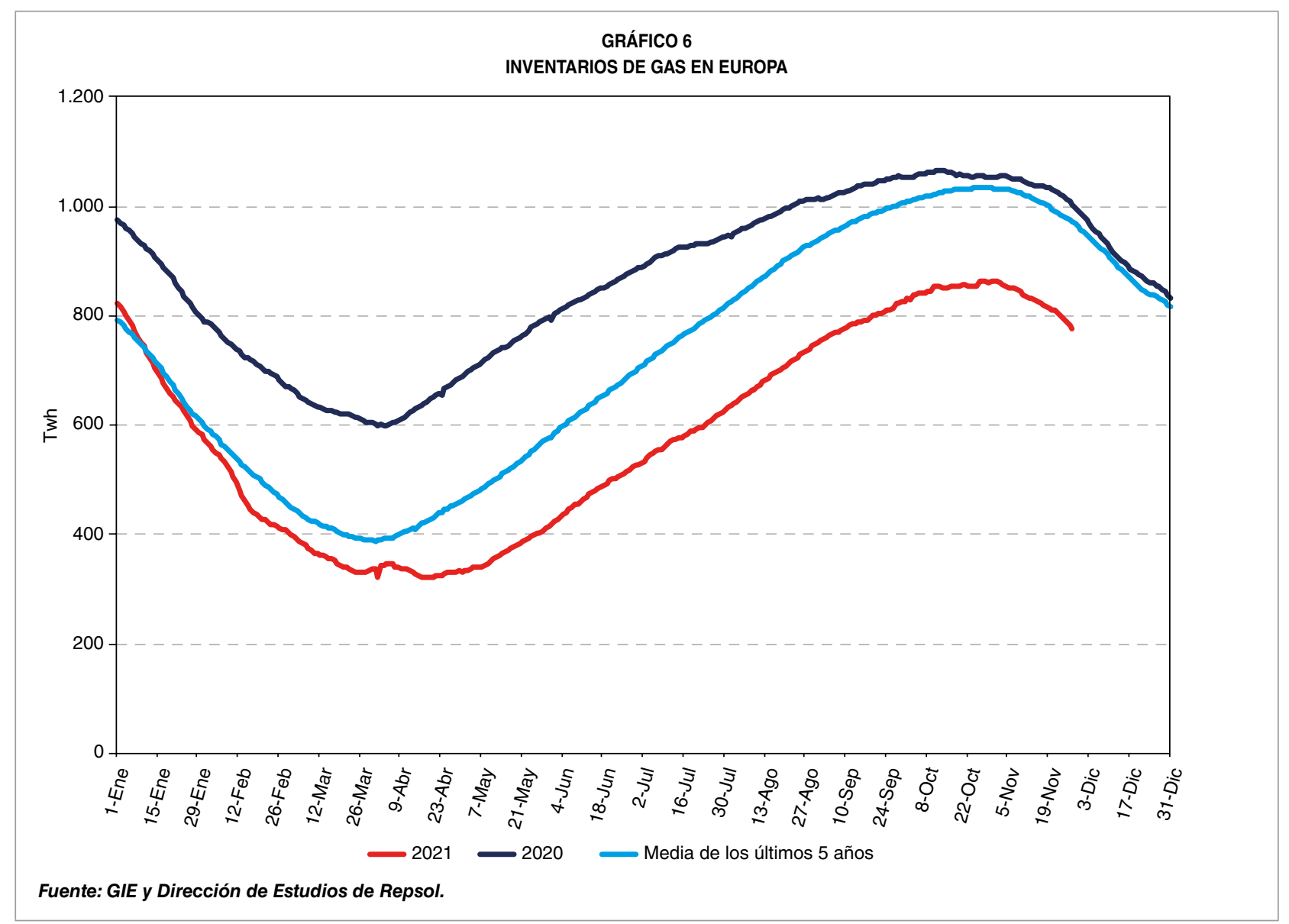

Respecto al mes pasado, se observa una inflexión en la curva de inventarios a medida que las temperaturas han comenzado a bajar en Europa. Las liberaciones netas comenzaron más de una semana antes de lo habitual en octubre y estuvieron por encima del promedio hasta la tercera semana de noviembre, aproximadamente. Los inventarios de gas europeos generalmente se reducen alrededor de un $50 \%$ en el periodo octubre-marzo en un invierno «normal». Un invierno frío puede suponer hasta un $10 \%$ adicional de liberaciones, mientras que el invierno más frío de los últimos diez años supuso una liberación adicional del 30\%.

En ausencia de cualquier cambio importante en el mix de generación, diversas fuentes apuntan a que sería necesaria una destrucción de la demanda de gas industrial este invierno para garantizar que el noroeste de Europa tenga sufi-

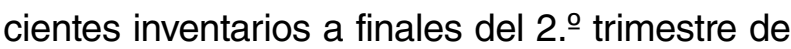
2022. Y para que se produzca tal destrucción y los niveles de inventarios no bajen drásticamen-

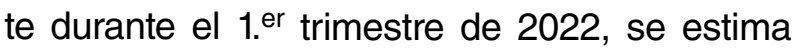
que el TTF debería de mantenerse por encima de los $80 € / M W h$ (más de 26 \$/MMBtu).

\subsection{España}

En el mes de noviembre, el MIBGAS se situó en un promedio de 83,4 €/MWh (próximo a los 28 \$/MMBtu), por debajo de los casi $90 € / M W h$ (30 \$/MMBtu) vistos en octubre.

Durante el mes de referencia, continuaron las fluctuaciones del precio del MIBGAS, que, de nuevo, se ha mantenido la mayor parte $D$ 
Raquel Martínez Farreres y Pedro Antonio Merino García
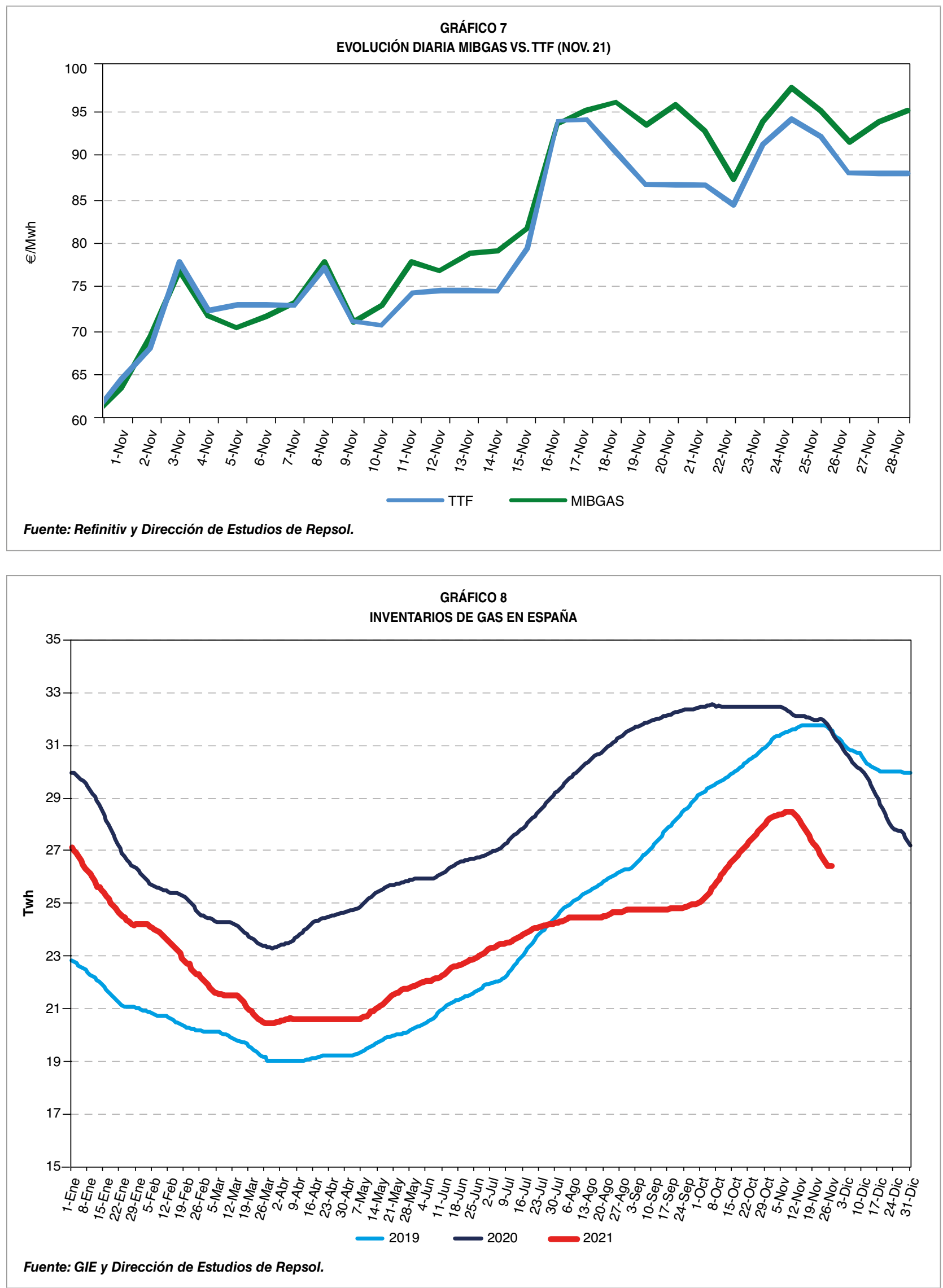


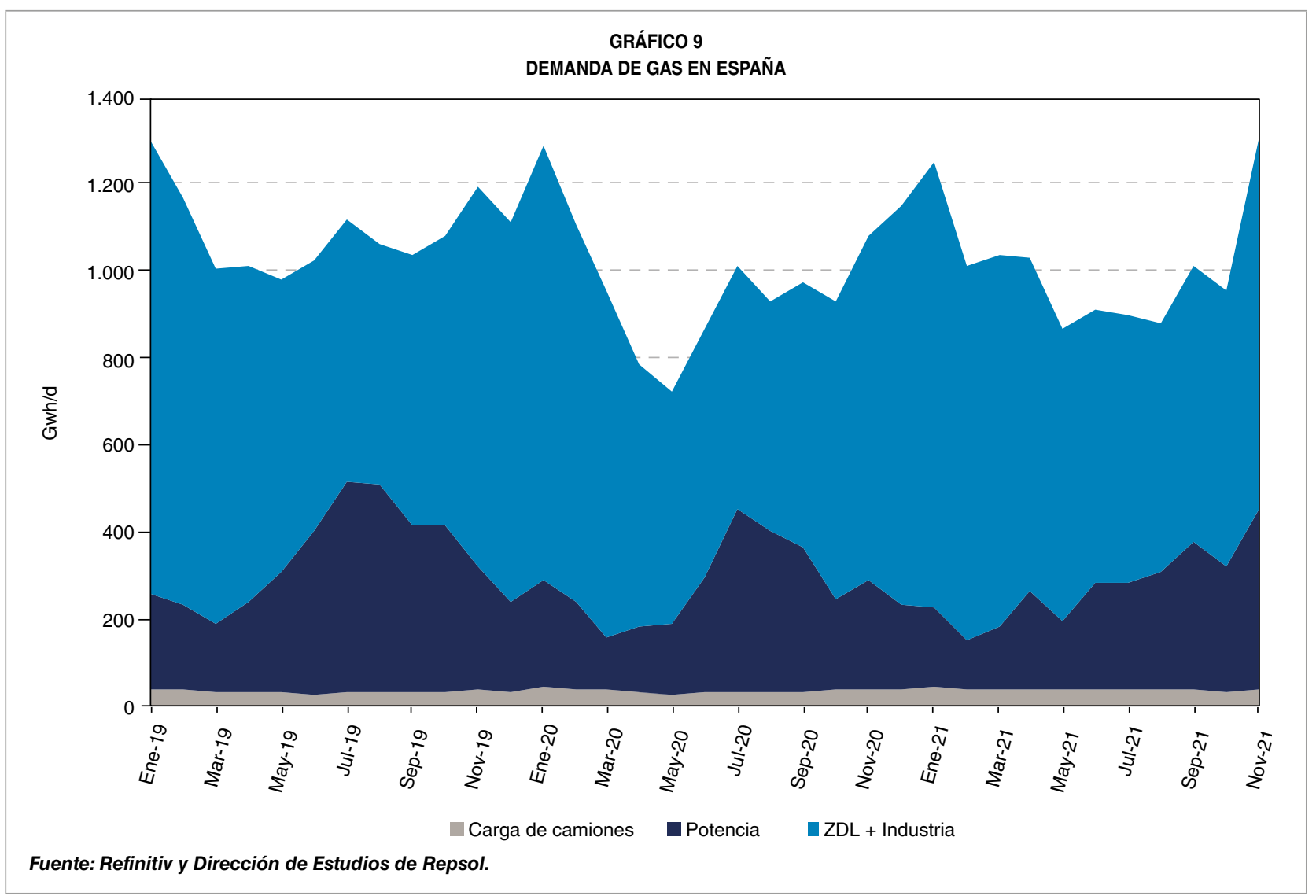

del mes por encima del TTF, es decir, continúa marcando «techo de cotización en los marcadores europeos».

Según datos del operador gasista Enagás, los inventarios de gas en España se han reducido alrededor de un $6 \%$ frente a octubre y se sitúan al $76 \%$ de su capacidad de llenado en $26 \mathrm{TWh}$. El pasado año se situaban en torno al $90 \%$ de su capacidad de llenado.

Esta caída coincide con un repunte de la demanda, que durante el mes de noviembre ha experimentado un importante repunte situándose en $1.310 \mathrm{GWh} / \mathrm{d}$, un $36 \%$ por encima de la registrada en octubre y un $21 \%$ por encima de la de noviembre de 2020.

Sectorialmente, a pesar del repunte en el consumo de gas para generación que aumentó más de un $40 \%$ frente a octubre, ante una menor entrada en el mix de las renovables, el verdadero repunte en términos netos ha venido de la mano de los sectores residencial/comercial e industrial, que, con un aumento aproximado del $36 \%$, han elevado la demanda total como consecuencia de unas temperaturas más bajas y un aumento del consumo de gas en el sector industrial debido a la moderada relajación de los precios vista este mes.

\subsubsection{Implicaciones para el mercado eléctrico}

El aumento de la demanda de electricidad, en el mes de noviembre respecto al mes de octubre, fue muy superior al de años anteriores como consecuencia de unas temperaturas más bajas de lo normal. Además, coincidió con el cierre planificado de tres centrales nucleares para su recarga y con unos precios de la $D$ 
electricidad muy altos en el exterior, lo que impulsó las exportaciones hacia Francia. Todo esto provocó que, a pesar del aumento de la generación eólica, fuera necesaria una mayor aportación de los ciclos combinados.

En promedio, el gas natural pasó a satisfacer un tercio del mix eléctrico del mes de noviembre (10,9 GW) entre los ciclos combinados y la cogeneración, abasteciendo casi un $40 \%$ de la demanda.

Este aumento de la utilización del gas, como fuente de generación eléctrica, provocó un aumento de las horas en las que los ciclos combinados marcaron el precio marginal, que supusieron el $24 \%$ de las horas. A pesar de esta mayor influencia del gas, el menor precio de este durante el mes de noviembre ha permitido que el precio de la electricidad en el mercado mayorista ( $p o o l)$ se redujese ligeramente desde los $200 € / M W h$ del mes de octubre hasta los $193 € / M W h$, en lo que ha sido el segundo mes con el precio más alto de la historia, situándose un $360 \%$ más caro que el año pasado.

Por otro lado, a pesar de que los ciclos combinados solo marcaron el precio en el $14 \%$ de las horas, la influencia de estos sobre el precio al que marca la hidráulica provocó que la influencia del precio del gas sobre el precio del pool eléctrico se diese al menos en el $60 \%$ de las horas, lo que provocó que la media del mercado mayorista de la electricidad durante el mes de octubre se situase en los $205 € / M W h$, rompiendo todos los récords, y situándose casi un $300 \%$ por encima de la media de los últimos diez años.

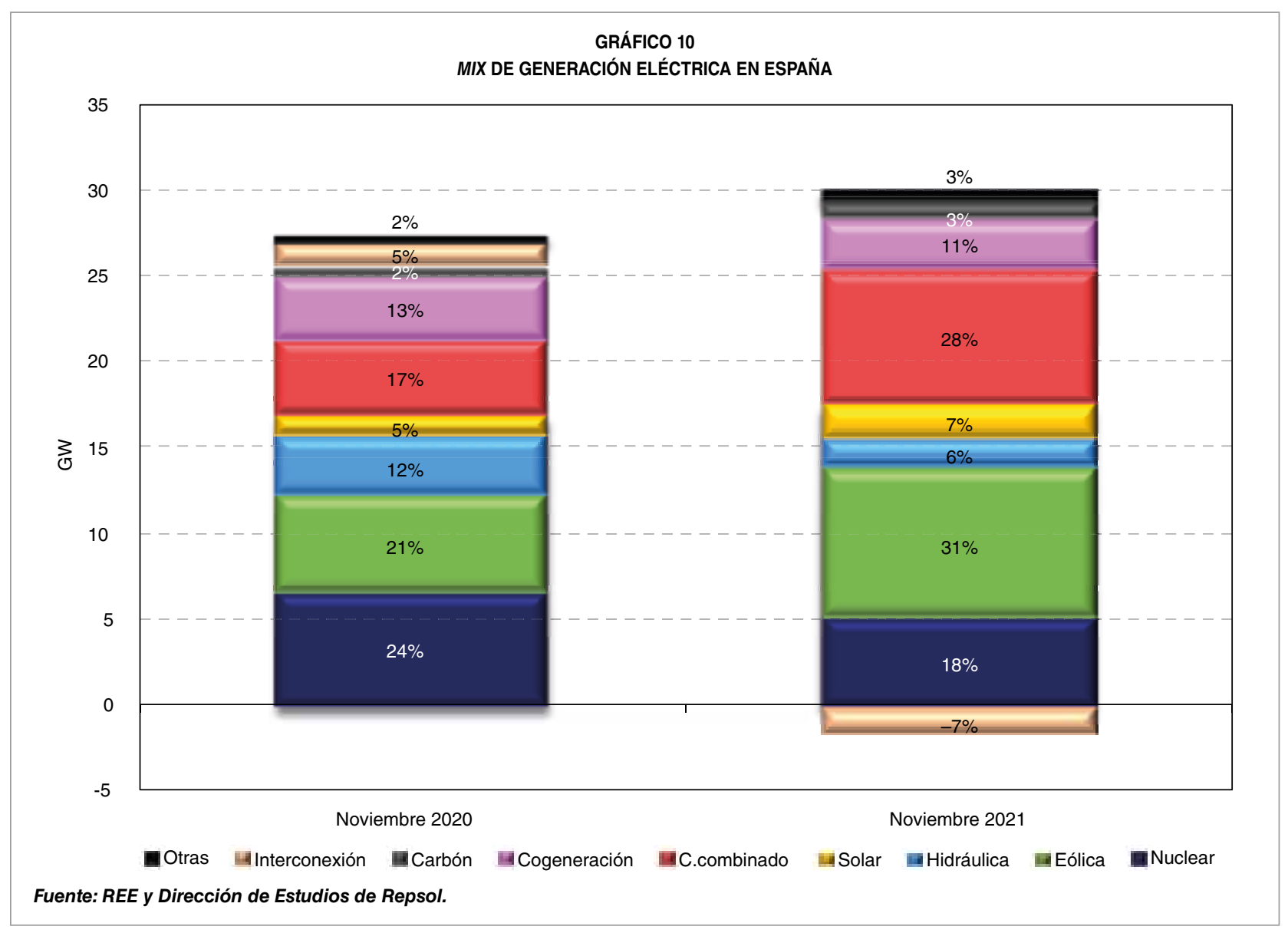




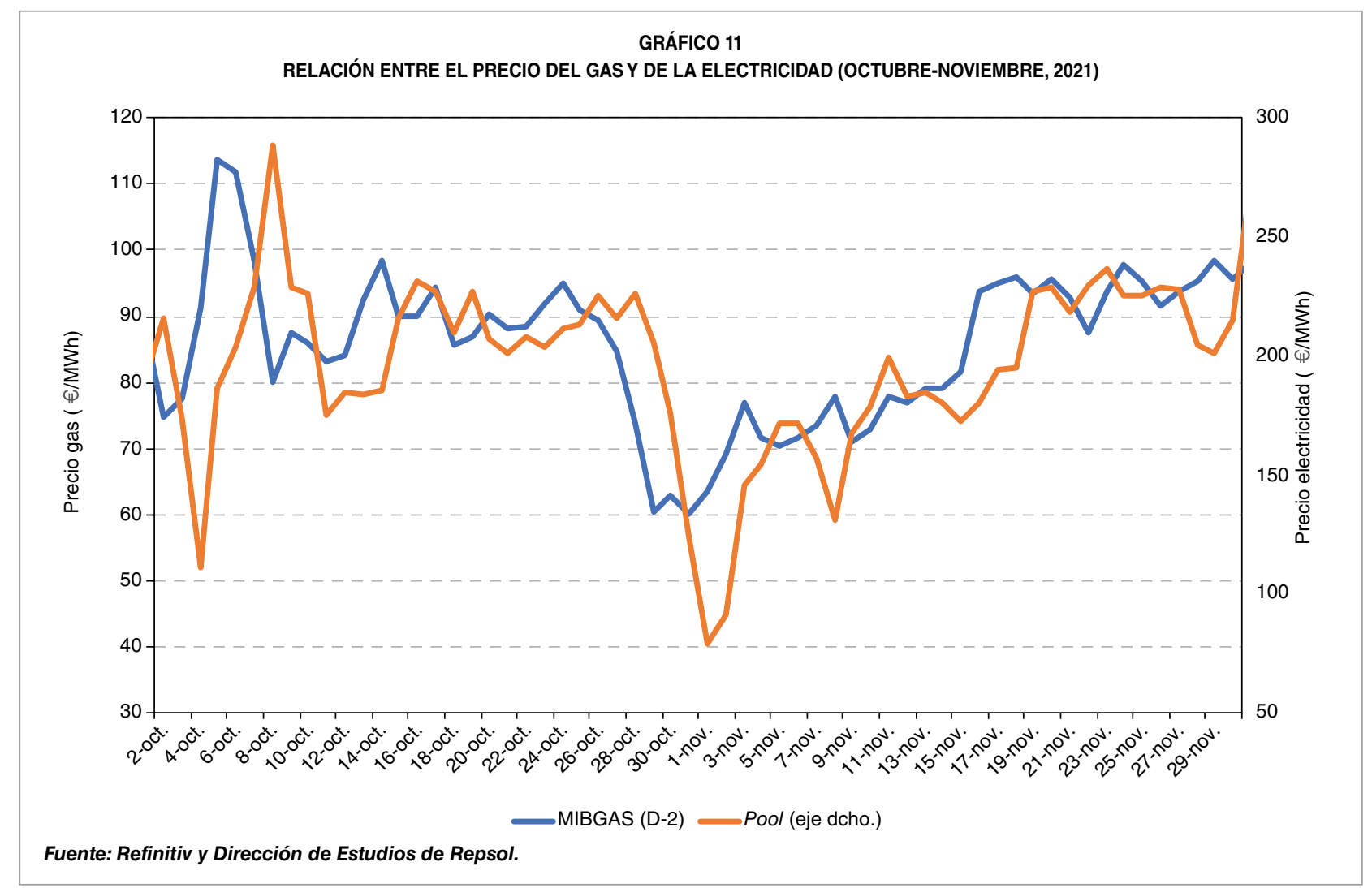

\subsection{Geopolítica}

La preocupación ante los reducidos flujos de gas recibidos de Rusia ha seguido marcando la geopolítica del gas durante el mes de noviembre.

Las preguntas acerca de cuál es el balance real del gas ruso, cuánto se destina al mercado doméstico, cuánto a la exportación y cuánto remanente existe de capacidad productiva siguen sin despejarse. Las intervenciones verbales desde el Kremlin se han espaciado, dando cierto respiro a un mercado muy reactivo, al mismo tiempo que se ha observado cierta inyección en los inventarios que Gazprom tiene en el noroeste de Europa, pero lo cierto es que los flujos adicionales siguen sin llegar.

Si bien es cierto que Rusia prioriza la cobertura de su demanda doméstica, también podría enfrentarse en las próximas semanas a algunas limitaciones de suministro propias. La producción rusa estaría (más o menos) en niveles récord, un $10 \%$ más que en 2020 hasta el tercer trimestre de 2021 y ligeramente por encima de los niveles de 2019. El impacto total de este aumento de la producción no ha sido sentido ni visto por Europa, ya que el objetivo a corto plazo (para el 1 de noviembre) era rellenar los niveles de inventarios nacionales. Se estima que Rusia podría aumentar los flujos en las próximas semanas, pero esto requeriría pagar por la capacidad de tránsito adicional o poner en marcha el Nord Stream 2. Pero la reciente paralización del proceso de certificación del Nord Stream 2 por parte del regulador alemán ha supuesto una nueva vuelta de tuerca en un asunto en el que queda mucho por resolver.

Y por si el mercado del gas europeo no estuviera suficientemente castigado por el $\triangleright$ 
temor constante ante la posible falta de suministro ruso, a mitad de noviembre, Alexander Lukashenko (presidente bielorruso) abrió otro frente potencial contra Europa, amenazando con cortar el suministro de gas que atraviesa su país. Estas declaraciones se dieron en un contexto de profunda crisis geopolítica, con migrantes arrastrados a la frontera de Polonia y con Europa pensando en recrudecer las sanciones económicas a Bielorrusia.

La «advertencia» de Lukashenko sacudió un mercado del gas en plena marejada de declaraciones acerca del suministro ruso a Europa. Además, el presidente bielorruso aprovechó estas declaraciones para recordar que su régimen autoritario todavía cuenta con el apoyo ruso, su aliado clave, y cuyos gasoductos de gas natural son críticos para los suministros europeos.

Por su parte, Rusia insistió en que no puede ejercer control ante este tipo de declaraciones y en que, al final, está en sus manos que Bielorrusia pueda «cortar» el suministro o no, puesto que ellos son la región productora.

Además de lo relativo a Rusia, otro hecho destacado acontecido en noviembre fue la celebración de la COP26 en Glasgow, que finalizó con un nuevo acuerdo en el que se pide una nueva reunión en un año y que los países traigan consigo objetivos de control de emisiones más agresivos. El papel del gas natural, a diferencia del papel del carbón, no fue señalado para ninguna política específica, pero, en general, las conclusiones extraídas fueron las siguientes:

- Descarbonización. El énfasis específico en la reducción del uso del carbón podría dar lugar un mayor uso del gas natural.

- Metano. Existe consenso en la reducción de las emisiones de metano en todo el sector energético, lo que podría reforzar las credenciales del gas natural como energía de transición, siempre y cuando controle sus propias emisiones de su cadena de valor.

- Aspectos económicos. Si bien a menudo se considera que el gas natural tiene un papel importante que desempeñar en la transición energética, existe el riesgo de que los grandes flujos de capital dedicados a la financiación «sostenible» reduzcan las inversiones necesarias en la cadena de valor del gas natural.

En realidad, se pospuso la toma de decisiones importantes a falta de consenso hasta el próximo año. Por lo tanto, habrá que esperar a que se materialicen los acuerdos.

\section{Expectativas a medio y largo plazo}

Según el World Energy Outlook (WEO), publicado el pasado mes de octubre por la Agencia Internacional de la Energía (AIE), la demanda de gas natural aumenta en todos los escenarios de proyección durante los próximos cinco años, pero a partir de entonces habrá fuertes divergencias.

En el STEPS (escenario energético de referencia de la AIE; incluye las políticas declaradas), la demanda de gas natural continuará aumentando después de 2025 y será alrededor de un $15 \%$ más alta en 2030 que en 2020. En el APS (Anounced Pledge Scenario, escenario energético con compromisos no formalizados en leyes), la demanda alcanzará su nivel máximo poco después de 2025 y luego disminuirá lentamente. En el NZE (escenario de energía a largo plazo con emisiones netas cero en 2050), la demanda caerá bruscamente después $\triangleright$ 


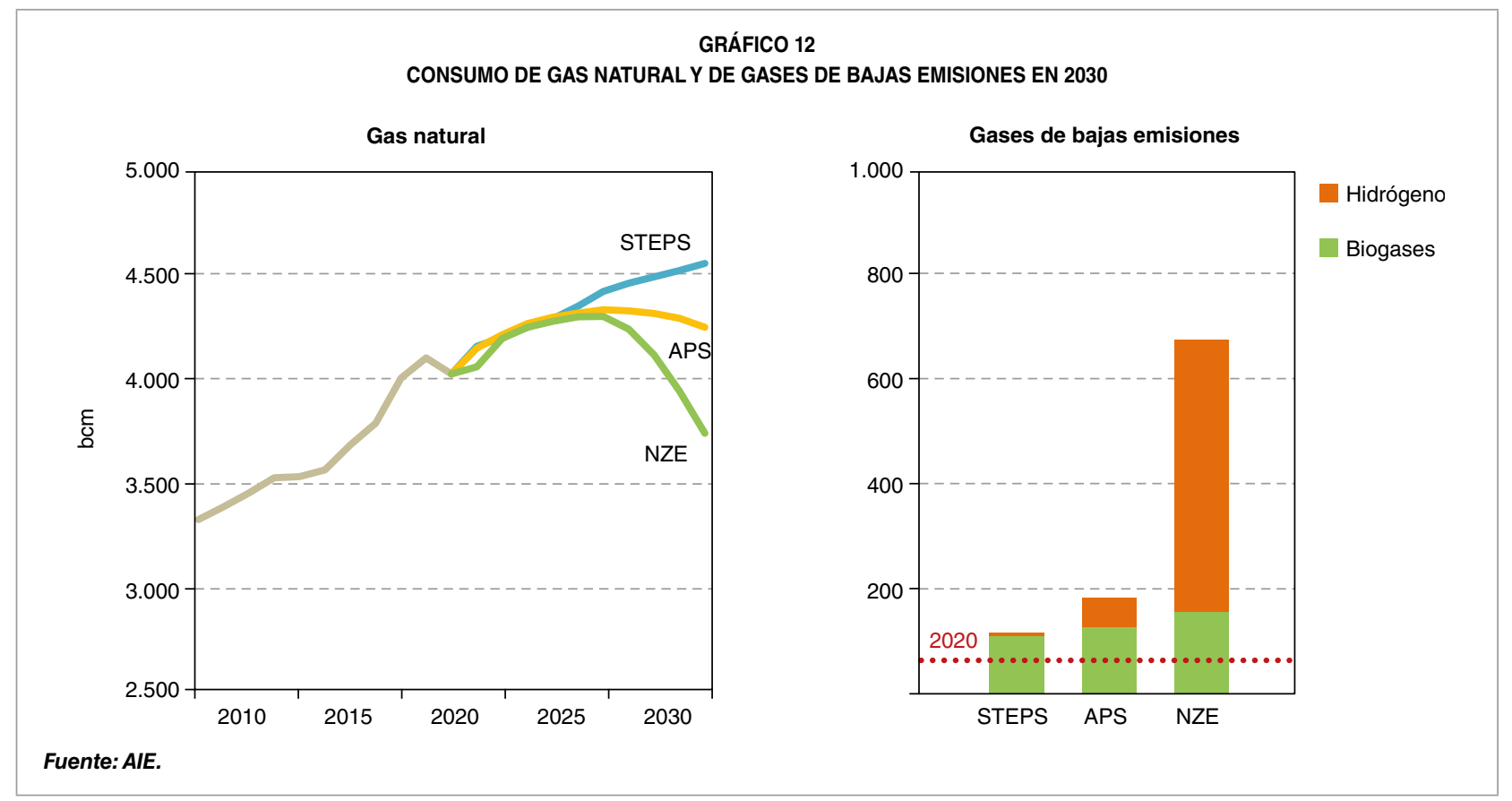

de 2025 y caerá muy por debajo de los niveles de 2020 para 2030. Sin embargo, la caída posterior a 2025 se verá parcialmente compensada por el crecimiento de la demanda de gases de bajas emisiones (incluido el hidrógeno bajo en carbono producido a partir de gas natural con CCUS -tecnología que permite la captura, el uso y el almacenamiento del $\mathrm{CO}_{2}-$ ). La demanda total de gases en el NZE en 2030 será alrededor de un $5 \%$ más alta que en la actualidad.

\subsection{Tendencia esperada del gas natural hasta 2030}

\subsubsection{Demanda}

En el STEPS, casi todo el aumento mundial, un $15 \%$, en la demanda de gas natural hasta 2030 viene de economías de mercados emergentes y en desarrollo. La demanda en China es un $40 \%$ más alta en 2030 que en 2020. Hay disminuciones en varios mercados maduros, incluidos Japón (un 25\% menos) y Europa, mientras que América del Norte y Corea ven un pico de demanda en 2025. La industria representa casi el $40 \%$ del crecimiento general de la demanda hasta 2030, liderada por los aumentos de la fabricación ligera en China e India, y del subsector químico en China.

En el APS, el aumento del $5 \%$ en la demanda mundial entre 2020 y 2030 enmascara grandes diferencias entre regiones y sectores. Esto incluye diferencias entre países objetivos descarbonizadores: en China y Corea, el consumo de gas aumenta hasta 2030 y se utiliza en gran medida para reemplazar combustibles más contaminantes, mientras que en Brasil, Canadá, la Unión Europea, Japón y EE. UU. la demanda se reduce en un 20-35\% (aunque hay una variación considerable entre varios Estados miembros de la Unión Europea). La demanda de gas natural tiende a crecer de manera más consistente en países sin objetivos de emisiones cero.

El cambio en la generación del carbón al gas es clave en la demanda futura de gas natural. $\triangleright$ 
Raquel Martínez Farreres y Pedro Antonio Merino García
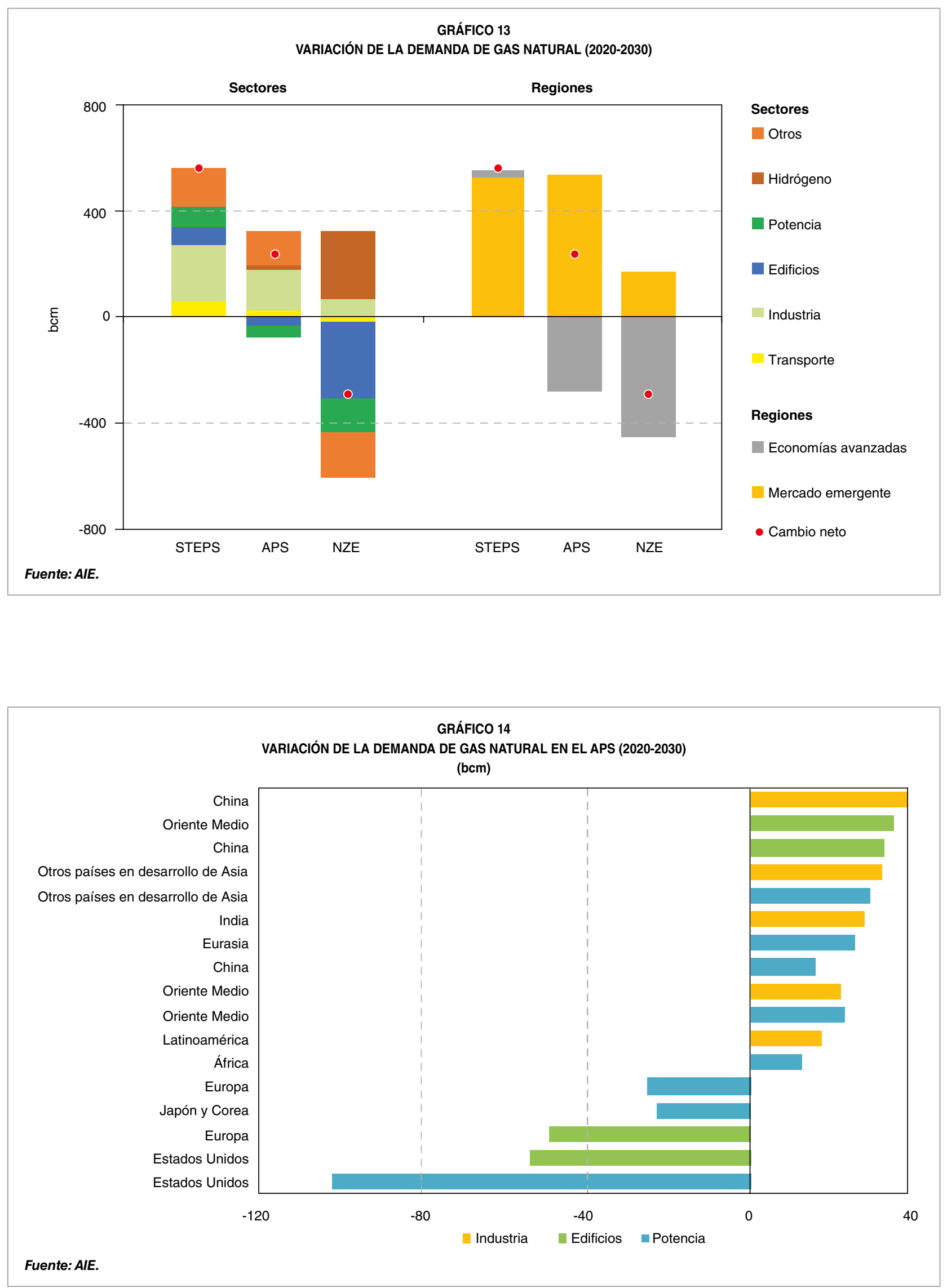
En el APS, alrededor de 100 bcm de gas adicional se utilizan para reemplazar el carbón en 2030, lo que evita alrededor de $180 \mathrm{Mt} \mathrm{CO}_{2}$ de emisiones al año. A nivel mundial, estos aumentos en la demanda de gas natural se compensan, en parte, por la caída de la demanda debido a las energías renovables, la eficiencia y la electrificación. También hay un cambio modesto pero importante del gas natural a la energía nuclear, la bioenergía moderna y los combustibles a base de hidrógeno, principalmente en EE. UU., Japón y la Unión Europea.

\subsubsection{Oferta}

En el STEPS, hay un aumento de $430 \mathrm{bcm}$ en la demanda de gas natural entre 2021 y 2030, mientras que las fuentes existentes de producción de gas convencional disminuyen en alrededor de $740 \mathrm{bcm}$. Los proyectos que ya han sido aprobados suman alrededor de $420 \mathrm{bcm}$ de producción en 2030, y el resto proviene de nuevas inversiones en alrededor de $460 \mathrm{bcm}$ por año de nuevos proyectos de gas convencional, y $230 \mathrm{bcm}$ de nuevos proyectos de gas no convencional. Alrededor de la mitad del aumento neto en el suministro de gas es para la exportación. Hay un aumento de 150 bcm en la capacidad anual de exportación de GNL, gran parte de ella en Qatar, EE. UU., Rusia y África Oriental. En el STEPS se requieren nuevos campos de gas, mientras que en el APS esta necesidad disminuye y en el NZE no hay necesidad de explotar campos nuevos de gas natural.

\subsection{Tendencia esperada del gas natural hasta 2050}

En el STEPS, la demanda de gas natural continúa aumentando a un ritmo más lento. No hay un pico de demanda, que alcanza los 5.100 bcm en 2050 , alrededor de un $30 \%$ más que en la actualidad. La demanda de gas natural en la industria sigue siendo el principal motor del crecimiento, pero su contribución al aumento $D$

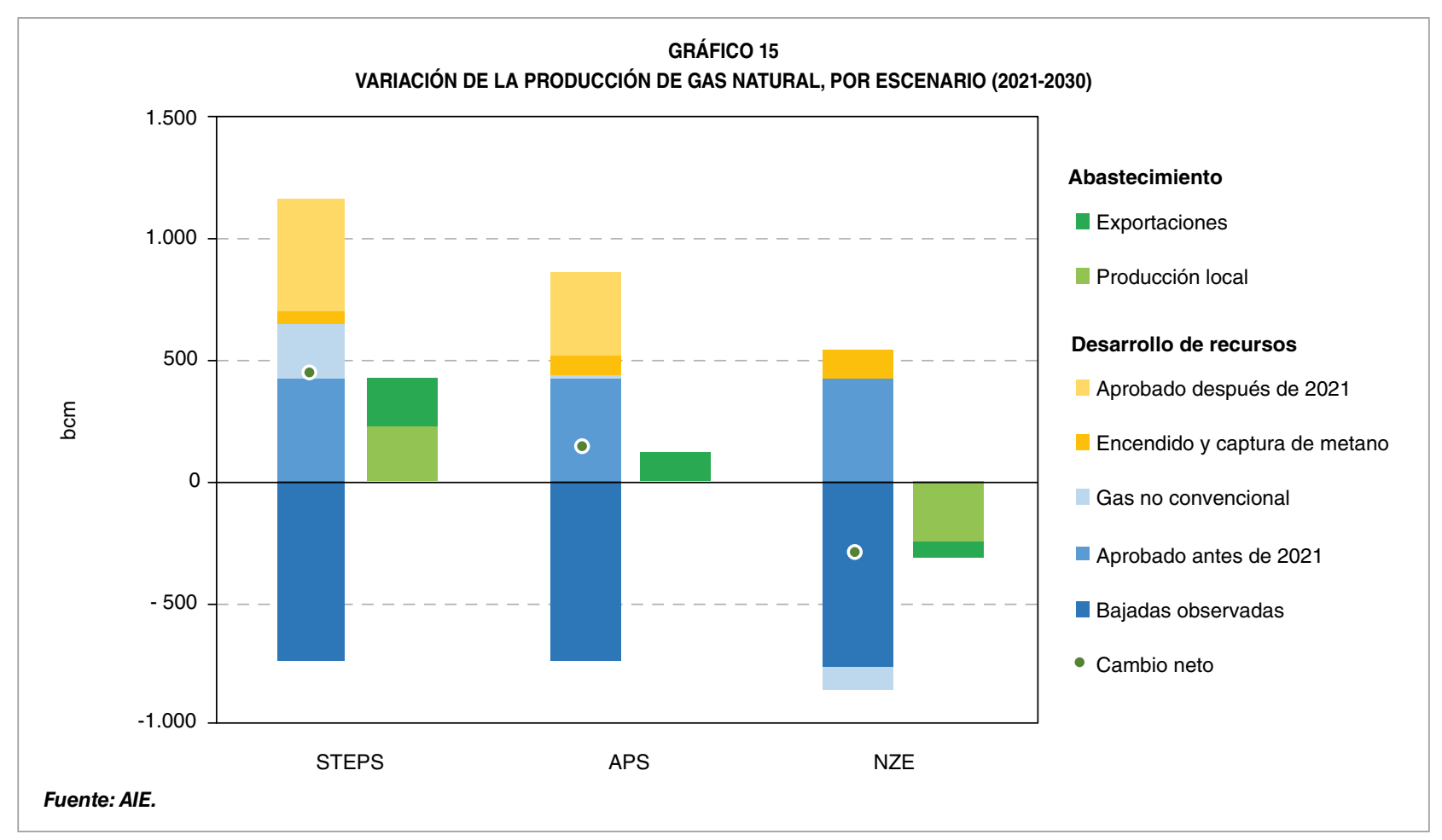




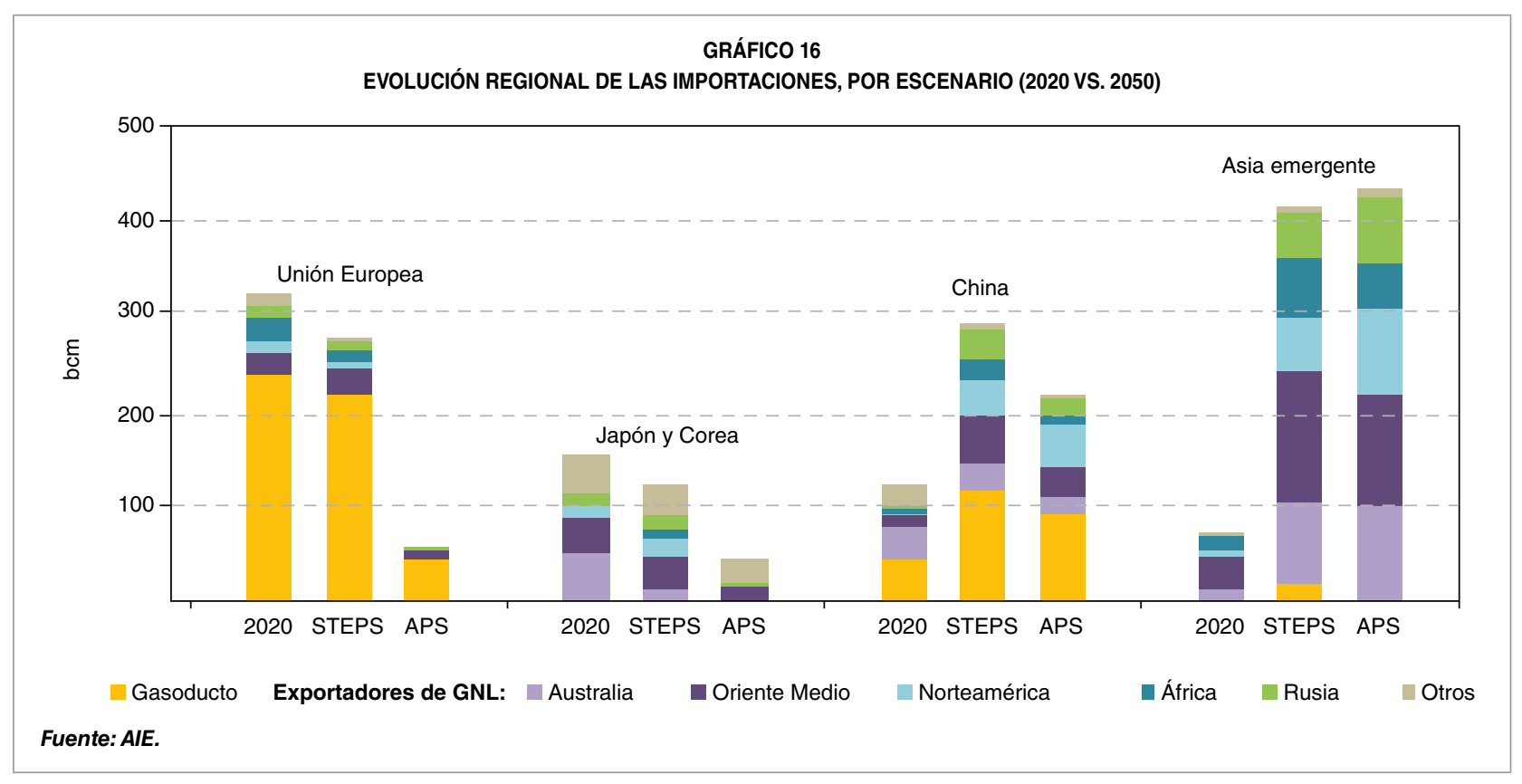

general de la demanda de energía disminuye a medida que las economías de mercados emergentes y en desarrollo hacen la transición a economías más orientadas a los servicios. Alrededor del $70 \%$ del aumento en el suministro proviene de Eurasia y Oriente Medio, y los volúmenes de gas comercializados internacionalmente aumentan en $450 \mathrm{bcm}$ durante este periodo. El comercio mundial de GNL continúa expandiéndose hasta alcanzar un $60 \%$ del comercio total de gas en 2050.

En el APS, la caída de la demanda doméstica en EE. UU. permite unos volúmenes de exportación mayor a países asiáticos. En la Unión Europea se produce un descenso de las importaciones en este mismo escenario a largo plazo.

\section{Conclusiones}

La situación actual del mercado del gas ha dado lugar a que, entre los agentes intervinientes en él, se definan dos corrientes de opiniones contrapuestas.
Por una parte, tenemos aquellos que opinan que este entorno de altísimos precios no viene sino a confirmar que es preciso una ruptura radical con los combustibles fósiles, incluyendo al gas natural, pensando en aquello de «muerto el perro, se acabó la rabia». Por otra, tenemos a aquellos que aseguran que, si bien la dependencia de combustibles fósiles es necesaria, el gas natural ha de estar presente en el proceso de transición; de hecho, afirman que se necesitará más gas para llevarlo a cabo con éxito, asegurando, en conjunción con las fuentes renovables, que la demanda energética se satisface.

El contexto de mercado que estamos viviendo ha reabierto dudas acerca de cómo abordar el tema de la transición a un sistema energético libre de emisiones. Lo que sí ha confirmado el exacerbado despunte de los precios es la necesidad de contar con una fuente energética "confiable» a un precio «razonable». Las cuestiones relativas a la garantía de suministro y a la necesidad de evitar precios desorbitados han quedado, por tanto, al descubierto una vez más. 
Con frecuencia, un futuro donde la demanda de combustibles fósiles está en declino ha sido presentado como un futuro donde el petróleo, el gas y el carbón son baratos (menor demanda, menor precio). Sin embargo, lo que se ha puesto de manifiesto con la actual «crisis energética» es que puede darse el caso de que desequilibrios entre oferta y demanda ajusten el mercado de forma que los precios coticen con fortísimas volatilidades y marcando precios extremos, lo que tiene un impacto directo en el mercado eléctrico, clave para el proceso descarbonizador.

En resumen, los precios son altos porque el gas disponible es actualmente escaso. Sin embargo, esta no es la cuestión fundamental. El problema más profundo es que el suministro flexible proporcionado por las fuentes fósiles, el «amortiguador» que protege al mercado de la volatilidad extrema, se ha erosionado gradualmente en todos los combustibles en favor del aumento de la generación con fuentes renovables (intermitentes), lo que ha exacerbado la volatilidad de los precios en el mercado. Y esta pérdida de flexibilidad lo que significa es que hemos entrado en un mundo de picos de precios, justo en el momento en que se está poniendo en marcha la transición energética y el proceso descarbonizador.

Una pregunta que genera interés es si estos episodios de alta volatilidad y precios se van a repetir con una frecuencia mayor en el futuro. Lo cierto es que hay que trabajar en asegurar el suministro incluso en los escenarios más ácidos. En un futuro descarbonizado y electrificado ha de existir espacio para la generación con energías de soporte, principalmente el gas. Sobre todo, en aquellas economías que están todavía en etapas de desarrollo menos maduras. El verdadero reto es resolver esta disparidad sin provocar un encarecimiento de la energía, que no haría sino añadir dificultad al propio proceso de transición. La desconexión entre electricidad y gas no es posible de manera inmediata. $Y$ todo sin olvidar la geopolítica, presente en todo el proceso, y que podría tensionar la relación entre países, a medida que el recurso fósil se concentra progresivamente en un menor número de productores. Habrá que ver cómo se aborda este asunto tan complejo desde las políticas energéticas y en la regulación.

\section{Bibliografía}

Corbeau, A. S. (2021). The Global Energy Crisis: Implications of Record High Natural Gas Prices. Center on Global Energy Policy. Columbia. School of International and Public Affairs. October 2021. https://www.energypolicy.columbia. edu/research/commentary/global-energy-crisisimplications-record-high-natural-gas-prices

IHS. (2021). Europe natural gas: ten questions on the region's power crunch. Executive briefings: oil and gas. November.

International Energy Agency. (2021a). World Energy Outlook 2021. https://www.iea.org/topics/worldenergy-outlook

International Energy Agency. (2021b). Gas Market Report, Q42021.https://www.iea.org/reports/gasmarket-report-q4-2021

Refinitiv. (2021). NBP \& TTF Front Month Report: NOV 21.

Sokolov, V. (2021). Gazprom plays games with Europe. Energy Intelligence. https://www.energyintel. com/0000017d-7022-d13d-af7f-f1a706aa0000 
